\title{
ALS-Linked Mutations Enlarge TDP-43-Enriched Neuronal RNA Granules in the Dendritic Arbor
}

\author{
LiQun Liu-Yesucevitz, ${ }^{1}$ Amy Y. Lin, ${ }^{1}$ Atsushi Ebata, ${ }^{1}$ Joon Y. Boon, ${ }^{1}$ Whitney Reid, ${ }^{2}$ Ya-Fei Xu, ${ }^{3}$ Kendra Kobrin, ${ }^{1}$ \\ George J. Murphy, ${ }^{2}$ Leonard Petrucelli, ${ }^{3}$ and Benjamin Wolozin ${ }^{1,4}$ \\ ${ }^{1}$ Department of Pharmacology and Experimental Therapeutics and ${ }^{4}$ Department of Neurology, Boston University School of Medicine, Boston, \\ Massachusetts $02118,{ }^{2}$ Center for Regenerative Medicine, Boston University School of Medicine and Boston Medical Center, Boston, Massachusetts 02118, \\ and ${ }^{3}$ Department of Neuroscience, Mayo Clinic, Jacksonville, Florida 32224
}

Trans-activating response region (TAR) DNA-binding protein of $43 \mathrm{kDa}$ (TDP-43) is an RNA-binding protein that is mutated in familial amyotrophic lateral sclerosis (ALS). Disease-linked mutations in TDP-43 increase the tendency of TDP-43 to aggregate, leading to a corresponding increase in formation of stress granules, cytoplasmic protein/RNA complexes that form in response to stress. Although the field has focused on stress granules, TDP-43 also forms other types of RNA granules. For example, TDP-43 is associated with RNA granules that are prevalent throughout the dendritic arbor in neurons. Because aggregation of TDP-43 is also important for the formation of these neuronal RNA granules, we hypothesized that disease-linked mutations might alter granule formation even in the absence of stress. We now report that ALS-linked mutations in TDP-43 (A315T and Q343R) increase the size of neuronal TDP-43 granules in the dendritic arbor of rat hippocampal neurons. The mutations correspondingly reduce the granule density, movement, and mobility of TDP-43 granules. Depolarization of rat hippocampal neurons with $\mathrm{KCl}$ stimulates TDP-43 granule migration into dendrites, but A315T and Q343R TDP-43 granules migrate shorter distances and into fewer dendrites than wild-type TDP-43. These findings highlight novel elements of TDP-43 biology that are affected by disease-linked mutations and suggest a neuronally selective mechanism through which TDP-43 mutations might elicit neuronal dysfunction.

Key words: G3BP; induced pluripotent stem cells; stress granule; TIA-1; trafficking; translation

\section{Introduction}

Accumulation of misprocessed protein aggregates is a hallmark of many neurodegenerative diseases. Trans-activating response region (TAR) DNA-binding protein of $43 \mathrm{kDa}$ (TDP-43) is the principle protein component that deposits to form the ubiquitinated inclusion bodies of patients with amyotrophic lateral sclerosis (ALS) and frontotemporal dementia (Neumann et al., 2006). Mutations in TDP-43 appear to be sufficient to cause ALS, with $>30$ different mutations in TDP-43 being associated with familial ALS (Da Cruz and Cleveland, 2011). These mutations appear to increase the propensity of TDP-43 to aggregate, although not all mutations have been investigated.

The structure of TDP-43 provides important insights into its functions. It was first identified as a transacting factor binding to

Received June 3, 2013; revised Jan. 26, 2014; accepted Feb. 10, 2014.

Author contributions: G.J.M. and B.W. designed research; L.L.-Y., A.Y.L., A.E., J.Y.B., W.R., Y.-F.X., and K.K. performed research; L.P. contributed unpublished reagents/analytic tools; L.L.-Y., G.J.M., L.P., and B.W. analyzed data; L.L.-Y. and B.W. wrote the paper.

This work was supported by the National Institutes of Health Grants ESO20395, NS066108, NS073679, and NS060872 to B.W.), the BrightFocus Foundation, the CurePSP Foundation, and the Alzheimer's Association. We thank Chelsea Trengrove for assistance.

B.W. has applied for a patent on compounds that inhibit TDP-43-containing stress granules. The remaining authors declare no competing financial interests.

Correspondence should be addressed to Benjamin Wolozin, Departments of Pharmacology and Neurology, Boston University School of Medicine, 72 East Concord St., R614, Boston, MA 02118-2526. E-mail: bwolozin@bu.edu.

DOI:10.1523/JNEUROSCI.2350-13.2014

Copyright $\odot 2014$ the authors $\quad 0270-6474 / 14 / 344167-08 \$ 15.00 / 0$ the promoter of HIV to repress Tat gene expression. The major protein domains of TDP-43 include two RNA-binding motifs (RRM1 and RRM2) that mediate binding to transcripts and a C-terminal glycine-rich region (GRR) that is required for interaction with other RNA-binding proteins such as hnRNP A1 and hnRNP A2/B1, which are known to participate in RNA granule biology (King et al., 2012). The GRR domain is also responsible for the characteristic ability of TDP-43 (and other RNA-binding proteins) to undergo reversible, regulated protein aggregation, which imparts the ability to consolidate RNA transcripts into the RNA/protein complexes termed RNA granules (Colombrita et al., 2009; Liu-Yesucevitz et al., 2010; Wolozin, 2012). RNA granules facilitate transport of transcripts along neuronal processes, regulate protein translation, and also process RNA for decay.

Most recent biological studies of TDP-43 have focused on its role in RNA transcription and splicing, which is its main function in non-neuronal cells. However in neurons, TDP-43 is also present in dendritic arbors, where it colocalizes with other major RNA-binding proteins in RNA granules, such as fragile X mentalretardation protein (FMRP) and staufen, known for their roles in RNA transport, localization, and protein translation (Wang et al., 2008; Fallini et al., 2012). Formation of RNA granules proceeds via aggregation of TDP-43. The tendency of disease-linked mutations to increase TDP-43 aggregation raises the possibility that these mutations also increase aggregation of TDP-43 to form RNA granules in dendritic arbors. 
To investigate the biology of dendritic TDP-43, we examined both endogenous TDP-43 and transduced TDP-43 in primary cultures of rat hippocampal neurons and in brains of mice overexpressing WT TDP-43. We observed that TDP-43 forms RNA granules in neuronal processes and synapses and that these granules colocalize with other major RBPs, such as TIA-1 and G3BP, but not the processing body (P-body)-associated Dcpla. Diseaselinked mutations modify the dynamics of dendritic TDP-43containing RNA granules, increasing granule size while reducing distribution density and mobility. Mutations in TDP-43 also cause striking decreases in depolarization $(\mathrm{KCl})$-evoked migration of TDP-43 into the dendritic arbor. Together, these studies indicate that mutations in TDP-43 perturb normal functions of neuronal RNA granules in the dendritic arbor and suggest changes in dendritic biology of TDP-43 as novel targets for disease-linked TDP-43 mutations.

\section{Materials and Methods}

Constructs. Plasmids expressing enhanced green fluorescent protein (EGFP)-tagged wild-type (WT), mutant, or C-terminal fragments of TDP-43 were generated by cloning cDNAs into a pEGFP-C1 vector (Clontech) at BamH1/XbaI sites. Plasmids expressing the red fluorescent protein (RFP)-tagged RNA granule markers Dcpla, TIA-1, or G3BP were generated by cloning cDNAs into a pRFP vector modified to express monomeric RFP (provided by Paul Anderson, Dana Farber Cancer Institute and Roger Tsien, University of California-San Diego). GIPZ lentiviral TDP-43 shRNAmi constructs (V3LHS_326405, V3LMM_445964, and V3LHS_636490) were purchased from Thermo Scientific.

Primary culture and transfection. Embryonic day 18 (E18) progeny from pregnant Sprague Dawley rats were killed by inhalation of $\mathrm{CO}_{2}$. Embryos were collected by cesarean section. Both male and female embryos were used. Hippocampi were removed and digested in 0.25\% trypsin in HEPES-buffered Hank's balanced salt solution (HBSS) without calcium or magnesium at $37^{\circ} \mathrm{C}$ for $15 \mathrm{~min}$. The hippocampi were washed three times with HBSS and manually dissociated with a pipette. Neurons were plated at a concentration of $25,000 / \mathrm{cm}^{2}$ on poly-L-lysine-coated glass coverslips or $35 \mathrm{~mm}$ culture plates with glass bottoms in plating media containing neurobasal media (Invitrogen) supplied with $0.5 \mathrm{~mm}$ glutamine, $10 \%$ fetal bovine serum, and $1 \%$ penicillin/streptomycin (100 $\mu \mathrm{g} / \mathrm{ml}$ ). After a $4 \mathrm{~h}$ incubation, neurons were attached to cover glasses and the medium was changed to a feeding medium consisting of neurobasal medium (Invitrogen) with B27 supplement, 1\% penicillin/streptomycin $(100 \mu \mathrm{g} / \mathrm{ml})$, and $0.5 \mathrm{~mm}$ glutamine. Primary hippocampal neurons were transiently transfected with lipofectamine 2000 at $7-10 \mathrm{~d}$ in vitro (DIV). The culture media were changed to opti-MEM (Invitrogen) prior to transfection and incubated for $30 \mathrm{~min}$ at $37^{\circ} \mathrm{C} / 5 \% \mathrm{CO}_{2}$. DNA plasmids/lipofectamine solution was prepared with a ratio of $1 \mu \mathrm{g}: 4 \mu \mathrm{l}$ and incubated for $25 \mathrm{~min}$ at room temperature before adding to primary neurons. Neurons were incubated at $37^{\circ} \mathrm{C} / 5 \% \mathrm{CO}_{2}$ for from $60 \mathrm{~min}$, washed once with Opti-MEM, and returned to feeding medium. Coverslips were used for immunocytochemistry in $48 \mathrm{~h}$.

STEMCCA lentivirus production, induced pluripotent stem cell generation and maintenance, and teratoma formation assay. hSTEMCCA virus production and concentration (Sommer et al., 2009; Sommer et al., 2010) and induced pluripotent stem cell (iPSC) generation, maintenance, and validation were performed as described previously by Sommer et al. (2009). For this study, fibroblasts from a 64-year-old male patient heterozygous for the G298S mutation were used to create three clonal disease-specific lines, one of which was used for this study. The control iPSC line used in this study was obtained from the Boston University and Boston Medical Center's Center for Regenerative Medicine comprehensive iPSC bank and was matched with the disease-specific line for age, sex, and ethnicity.

Generation of neuronal-lineage cells from iPSCs. Neuronal-lineage cells were generated as described previously by Chambers et al. (2009) and Hu et al. (2009). For immunofluorescence visualization of TUJ1, MAP2, and ChAT, cells were grown on $18 \mathrm{~mm}$ glass coverslips coated with $5 \mathrm{mg} / \mathrm{ml}$ fibronectin and $10 \mathrm{mg} / \mathrm{ml}$ laminin (for TUJ1 and MAP2 labeling) or Matrigel (for ChAT labeling). Cells were fixed with 4\% PFA in PBS and permeabilized and blocked with 5\% BSA in PBS with $0.1 \%$ Triton X-100. Primary and secondary antibody staining were performed in PBS/ $0.005 \%$ Triton X-100. Primary antibodies were mouse anti-human Tuj1 and mouse anti-human MAP2 (both Sigma-Aldrich) and rabbit antihuman ChAT (Millipore). Secondary antibodies were donkey antimouse $594 \mathrm{~nm}$ and donkey anti-rabbit $488 \mathrm{~nm}$ (both Jackson ImmunoResearch). Cell nuclei were labeled with DAPI (Invitrogen) after antibody incubations and final washes. TDP-43-positive cytoplasmic granules were quantified by measuring the number of cytoplasmic granules per cell $(n=45-116)$ in cultures of control and G298S motor neuron $(\mathrm{MN})$ iPSC lines from four separate experiments.

Fluorescent immunocytochemistry. Primary hippocampal neurons were washed with $1 \times$ PBS, fixed with $4 \%$ paraformaldehyde for $10 \mathrm{~min}$ at room temperature, washed three more times in PBS, permeabilized by incubation in $0.1 \%$ Triton $\mathrm{X}-100 / 1 \times \mathrm{PBS}$ for $10 \mathrm{~min}$ at room temperature, washed three times with $1 \times \mathrm{PBS}$ for $5 \mathrm{~min}$ at room temperature, and incubated in $0.1 \mathrm{~m}$ glycine and $0.2 \mathrm{M}$ Tris- $\mathrm{Cl}, \mathrm{pH} 8$, for $10 \mathrm{~min}$ at room temperature. Neurons were blocked for $1 \mathrm{~h}$ in PBS containing 5\% BSA, incubated in primary antibodies for $1 \mathrm{~h}$ at room temperature, washed three times with $1 \times \mathrm{PBS}$, detected with secondary antibodies, and washed three times with $1 \times$ PBS. Coverslips were mounted on glass slides with ProLong Gold antifade mounting reagent (Invitrogen). The primary antibodies used were rabbit anti-TDP-43 (Proteintech Group), rabbit antiTDP-43 (Cosmo Bio), goat anti-TIA-1 (Santa Cruz Biotechnology), and mouse anti-MAP2 (Millipore). The secondary antibodies used were Dylight 488-conjugated donkey anti-rabbit, Dylight 549-conjugated donkey anti-rabbit, Dylight 549-conjugated donkey anti-goat, and Dylight 405-conjugated donkey anti-goat (all Jackson ImmunoResearch) and Alexa Fluor 549-conjugated donkey anti-mouse (Invitrogen).

Microscopy. Cells or tissue slides were visualized by 3D multiple wavelength fluorescence microscopy using the Zeiss LSM510 or 710 LSM Meta confocal microscope for Dylight 405, Dylight 545, and Dylight 488 fluorescence at room temperature using an oil-immersion $63 \times \alpha$-planApochromat objective. The images were captured using an HP CoolSNAP camera and examined as either single sections or projections of an entire stack of optical sections. All images from immunocytochemistry were processed using ImageJ software and Adobe Photoshop CS4. Images used for quantification were processed in MetaMorph software.

Activity-dependent TDP-43 granule translocation. Hippocampal neuron culture prepared from E18-E19 rat embryos were plated on coverslips and transfected at 7 DIV with EGFP-tagged TDP-43 or mutant TDP-43 (A315T or Q343R). Twenty-four hours after transfection, neurons were pretreated with $1 \mu \mathrm{M}$ tetrodotoxin (TTX) for $1 \mathrm{~h}$ and then cells were stimulated 4 times with $90 \mathrm{~mm} \mathrm{KCl}$ for $3 \mathrm{~min}$ and allowed to recover for $10 \mathrm{~min}$ after each stimulation. TTX was also present during the intrastimulation and poststimulation phases $(6 \mathrm{~h})$. Cells were fixed and immunostained with anti-postsynaptic density-95 rabbit mAb (Cell Signaling Technology) and Alexa Fluor 594 donkey anti-rabbit IgG (Jackson ImmunoResearch). Fluorescent images were taken on a Zeiss laser confocal microscope (LSM 700) with a plan-apochromat $40 \times / 1.3$ oil objective using 405, 488, and $555 \mathrm{~nm}$ lasers for DAPI, GFP, and Alexa Fluor 594, respectively. The image analysis was performed with the software package ImageJ (Schneider et al., 2012). Neurites were traced and their length was measured with the NeuronJ plugin (Meijering et al., 2004). The number of neurites traced was manually counted.

Live cell imaging: fluorescence recovery after photobleaching and timelapse particle tracking. Cultured E18 hippocampal neurons were cultured on poly-L-lysine-coated MatTek $35 \mathrm{~mm}$ glass-bottom dishes. On DIV 10, $48 \mathrm{~h}$ posttransfection with EGFP-tagged TDP-43, primary hippocampal neurons were analyzed by microscopy. The Zeiss TempModule system was used to control the temperature $\left(37^{\circ} \mathrm{C}\right)$, humidity, and $\mathrm{CO}_{2}(5 \%)$ of the working system. Neurons were allowed to equilibrate to $37^{\circ} \mathrm{C} / 5 \%$ $\mathrm{CO}_{2}$ in the heated, stage-mounted humidity chamber for $30 \mathrm{~min}$ before imaging. A Zeiss LSM 710 confocal laser scanning microscope was used to capture all live cell imaging and videos. For fluorescence recovery after photobleaching (FRAP) experiments, a representative TDP-43 granule was selected with the $100 \times$ objective $(\alpha$-plan-Apochromat $100 \times / 1.46$ 

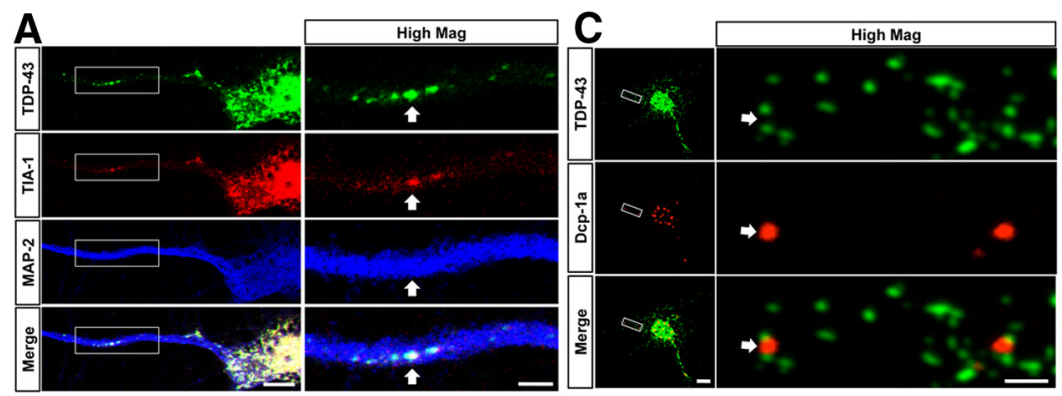

E

\begin{tabular}{|c|c|}
\hline IB: Anti-TDP-43 Soluble \\
\hline F & $\overline{0}$ \\
\end{tabular}
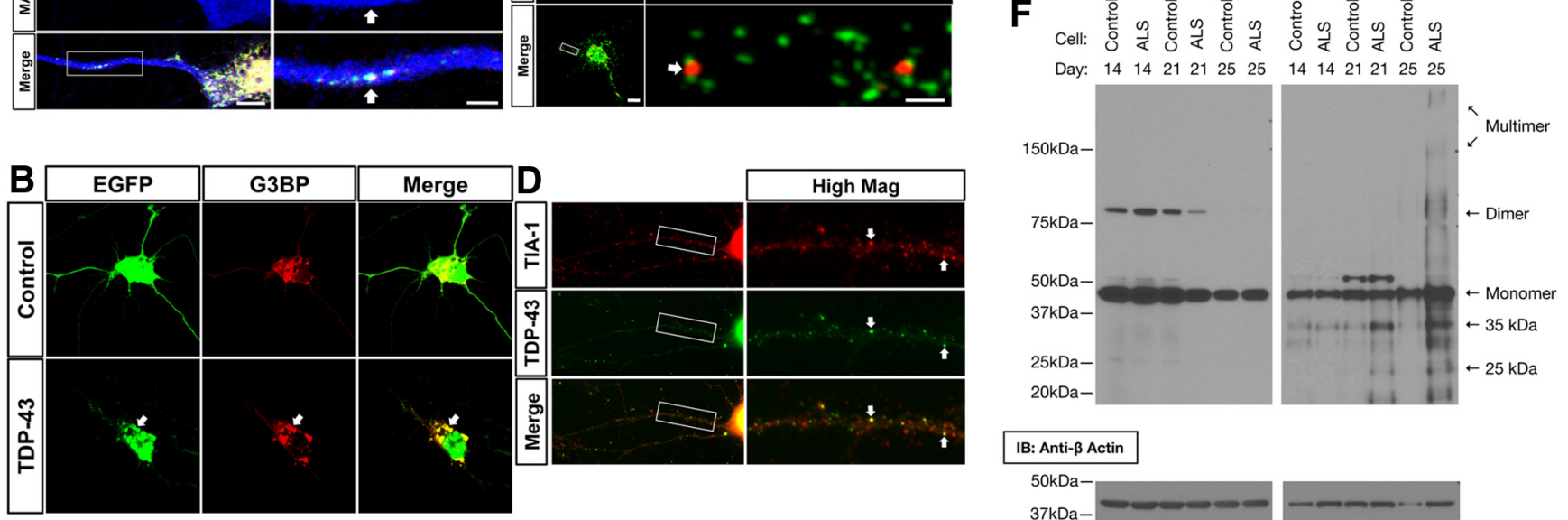
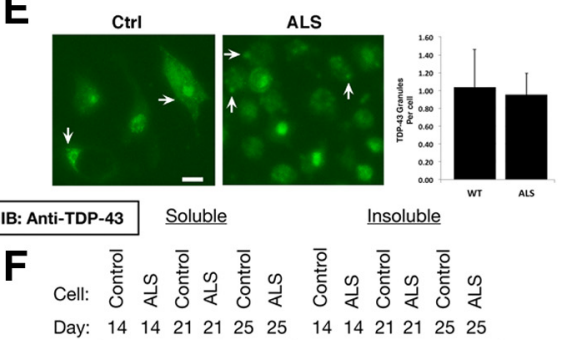

Insoluble

IB: Anti- $\beta$ Actin

$50 \mathrm{kDa}$

$37 \mathrm{kDa}-$

Figure 1. TDP-43-enriched RNA granules colocalize with stress granules. A, Representative images from a primary hippocampal neuron expressing EGFP WT TDP-43 and RFP-TIA-1. Endogenous MAP2 (blue) was detected by immunocytochemistry. Scale bar, $10 \mu \mathrm{m}$. Higher magnification of the boxed images of the dendrite showed that dendritic WT TDP-43-enriched RNA granules colocalize with stress granules. Scale bars, $2 \mu \mathrm{m}$. $\boldsymbol{B}$, Representative primary hippocampal neuron coexpressed EGFP-WT TDP-43 and RFP-G3BP. WT TDP-43-enriched RNA granules colocalize with stress granules in neuronal soma but not neuronal processes. Arrows point to colocalized RNA granules. Scale bar, $10 \mu m$. C, Coexpression of EGFP-WT TDP-43 and RFP-Dcp1a in a representative primary hippocampal neuron. Scale bar, $10 \mu \mathrm{m}$. Higher magnification of the boxed images showed WT TDP-43-enriched RNA granules express adjacent to P-bodies. Scale bars, $2 \mu \mathrm{m}$. $\boldsymbol{D}$, Fluorescent immunocytochemistry was applied to detect endogenous WT TDP-43 (green) and TIA-1 (red). In neuronal process from a representative DIV 20 hippocampal neuron, higher-magnification images were captured and show that some WT TDP-43-enriched RNA granules contain TIA-1. Scale bars, $10 \mu \mathrm{m}$. E, Expression of TDP-43 in MN iPSCs from neurologically normal (Ctrl) and ALS human lines, with quantification on the right. Arrows point to TDP-43 granules. Scale bar, $10 \mu \mathrm{m}$. $\boldsymbol{F}$, Immunoblot of TDP-43 from MN iPSCs from control and familial ALS (G298S) donors. Increased levels of multimeric, insoluble TDP-43 was present in in the familial ALS line at 21 and $28 \mathrm{~d}$ of culture after differentiation.

oil). To capture images, nominal speed 9 was used and the pinhole was set to $2 \mu \mathrm{m}$ to obtain strong fluorescence. Control images were captured before bleaching. Then, the granule of interest was bleached with $100 \%$ argon laser power and a series of images was captured immediately after bleaching. Low laser transmission was used for capturing images to avoid photobleaching the entire image. Images were captured every $2 \mathrm{~s}$ for $160 \mathrm{~s}$ after bleaching. The fluorescence intensity of the target granules was curve fit with a one-phase exponential equation in Zen software (Zeiss) to calculate the mobile and immobile fractions. Data were plotted in Prism software (GraphPad) to produce a FRAP graph. For time-lapse particle tracking, time-lapse photography allowed for the capture of images every $20 \mathrm{~s}$ for $10 \mathrm{~min}$ with the $\alpha$-plan-Apochromat $63 \times$ oil objective. The motility rate of the TDP-43 granules was analyzed in MetaMorph software using single particle tracking and multidimensional motion analysis application. The motility rates of $>500$ TDP- 43 granules from nine neurons of three independent experiments were collected for quantification.

Image analysis and quantification. DIV7 primary hippocampal neurons were cotransfected with constructs expressing mCherry and EGFPTDP-43. Individual dendrites were highlighted by mCherry fluorescence. The furthest distance TDP- 43 granule in a dendrite was defined by tracing the dendritic distance from the cell body to the furthest location where TDP-43 granules were identified. Granule density was quantified by counting the number of granules in a $20-\mu \mathrm{m}$-long dendritic segment. On average, 40 processes from 12 different neurons in each group were analyzed. ImageJ software was used to quantify dendritic distance and granule density. RNA granules located in neuronal soma were excluded from quantification. MetaMorph Morphology filters were applied to images before data collection. The RNA granule size and fluorescence intensity were measured in MetaMorph software. Data were analyzed in GraphPad Prism software.

\section{Results}

\section{TDP-43-enriched RNA granules localize in neuronal processes}

A striking hallmark of TDP-43 proteinopathy in ALS is the deposition of protein inclusions in the processes and cytoplasm of neurons. Reports from multiple investigators, including us, indicate that TDP-43 regulates RNA metabolism by participating in the biology of stress granules, a subtype of RNA granules (Colombrita et al., 2009; Liu-Yesucevitz et al., 2010; Dewey et al., 2011; Bentmann et al., 2012; Wolozin, 2012).

We began our studies by characterizing TDP-43-enriched neuronal RNA granules in primary hippocampal neurons. DIV 10 rat hippocampal neurons were transiently transduced with TDP-43 and TIA-1 (Fig. 1A), G3BP (Fig. 1B), or Dcp1a (Fig. 1C). TIA- 1 and G3BP are RNA-binding proteins associated with stress granules and Dcpla is associated with P-bodies (Liu-Yesucevitz et al., 2010). RNA granules containing both TDP-43 and TIA-1 were present in both neuronal soma and dendrites (Fig. 1A). Similar results were observed when examining endogenous TDP43, which formed smaller granular puncta that colocalized TIA-1, a stress granule marker (Fig. 1D). In contrast, RNA granules containing both TDP-43 and G3BP were largely located in the soma (Fig. 1B). TDP-43-enriched RNA granules did not colocalize with Dcpla, a marker for P-bodies, but they did appear as granules adjacent to P-bodies (Fig. 1B). More than $50 \%$ of the neurons examined exhibited dendritic TDP-43 (both transfected and endogenous); the fraction of neurons with TDP-43 present in the soma and dendrites appears to be condition dependent, with both stress and depolariza- 
tion increasing exit of TDP-43 from the nucleus (Wang et al., 2008; Colombrita et al., 2009; Dewey et al., 2011).

We also examined endogenous TDP-43 in MN iPSCs from control and familial ALS (G298S TDP-43) subjects. Our prior studies indicated that differentiation produces cells with neuronal morphologies, expression of neuronal antigens such as MAP2, and expression of MN antigens (Leung et al., 2013). TDP-43 was present in the MN iPSCs in both the nucleus and soma (Fig. 1E). MN iPSCs from control and ALS subjects that had been differentiated for $<2$ weeks exhibited cytoplasmic TDP-43 granules (Fig. 1E, arrows); however, the number of cytoplasmic granules per cell were not significantly different among the groups (Fig. 1E). Further biochemical studies suggested that, with increasing duration of culture, mutant TDP- 43 exhibited an increasing tendency to accumulate high-molecular-weight multimers and lower-molecular-weight fragments (Fig. $1 F$ ). We used biochemical fractionation and immunoblotting to examine the characteristics of TDP-43 in the MN iPSCs with time because TDP-43 granule formation is associated with formation of insoluble aggregates (Liu-Yesucevitz et al., 2010; Dewey et al., 2011; Hart and Gitler, 2012). The biochemical characteristics of TDP-43 in the MN iPSCs varied with age of differentiation and genotype (Fig. $1 F$ ). Sarkosyl-stable, multimeric TDP-43 and smaller, 25/35 KD TDP-43 cleavage fragments were not apparent 2 weeks after differentiation, but became increasingly apparent with time (Fig. $1 F$ ). By $25 \mathrm{~d}$ of differentiation, Sarkosyl-insoluble oligomeric TDP-43 and the putative TDP-43 cleavage fragments were apparent and accumulated to a greater extent in the $\mathrm{MN}$ iPSCs carrying G298S TDP-43 than WT TDP-43 (Fig. $1 F$ ). The appearance of biochemical differences in TDP- 43 solubility with increasing duration shows that the appearance of insoluble TDP-43 is sensitive to conditions and raises the possibility that the G298S TDP-43 mutation elicits a change in TDP-43 biology that only appears with time. However, results observed from individual lines could be influenced by the genetic background of the donor or by clonal variation. To understand whether diseaselinked changes in TDP-43 could alter its neuronal physiology, we examined the behavior of exogenously expressed WT and mutant TDP-43 in hippocampal neuronal cultures.

\section{ALS-linked mutations change the size and distribution of neuronal RNA granules}

Recent studies have indicated that ALS-linked mutations in TDP-43 increase its stability, increase its association with stress granule proteins, induce toxicity, and accelerate disease onset time (Liu-Yesucevitz et al., 2010; Watanabe et al., 2013). To elucidate the effects of disease-linked mutations on TDP-43enriched neuronal RNA granules, we investigated the size and distribution of TDP-43 RNA granules in primary hippocampal neurons. EGFP-tagged WT TDP-43 or mutant TDP-43 (A315T or Q343R) was coexpressed with plasmids expressing mCherry in DIV 10 primary hippocampal neurons (Fig. 2A). The expression of mCherry was used to highlight the transfected neurons, outlining neuronal soma and processes. To measure a dendritic length, we traced the distance from the soma to the end of the processes highlighted by mCherry. The size and fluorescent intensity of TDP-43 RNA granules were measured using MetaMorph software. RNA granules formed by A315T or Q343R TDP-43 were larger (Fig. 2B,C) and exhibited greater fluorescence intensity than those formed by WT or K82/84A TDP-43 (where K82/84A is expressed only outside the nucleus in the cytoplasm because it lacks the TDP-43 nuclear localization signal; Fig. 2E). The distribution of TDP-43 RNA granules along the dendrites was determined by dividing dendrites into $20 \mu \mathrm{m}$ segments and quantifying the number of granules in each $20 \mu \mathrm{m}$ segment. RNA granules containing A315T or Q343R TDP-43 exhibited lower distribution densities than either WT or K82/84A TDP-43 (Fig. 2B,D). The farthest distance of distribution for TDP-43 granules was determined by measuring the distance from the soma to the farthest TDP-43 RNA granule identified along a process; however, no significant differences were observed (data not shown). Therefore, mutations in TDP-43 alter the size and distribution density of RNA granules. The absence of changes in these measures observed for the K82/84A mutant demonstrated that these changes were independent of cytoplasmic levels of TDP-43.

To test the effects of mutations on TDP-43 granule formation using an independent method, we measured the mobility of TDP-43 using FRAP (Sprague and McNally, 2005). EGFP-tagged WT or A315T TDP-43 were transiently expressed in DIV 10 rat primary hippocampal neurons and FRAP was performed $2 \mathrm{~d}$ after transfection. Images were captured with a $4 \times$ zoom every $2 \mathrm{~s}$ and data were analyzed in Zeiss Zen software. Dendritic RNA granules with similar sizes were selected for this experiment from each group. The average fluorescence intensity for RNA granules from a representative cell was plotted as a function of time after correction for total cell bleaching (Fig. $2 F$ ). The mobile fraction of a TDP-43 RNA granule was determined by comparing the fluorescence intensity in the bleached region after the equilibrium is reached with the intensities before and immediately after bleaching. The mobile fraction of mutant TDP-43-enriched RNA granules $(32.81 \%)$ was less than that of WT TDP-43-enriched RNA granules (47.66\%; Fig. $2 F$ ). These data demonstrate that diseaselinked mutations in TDP-43 modify RNA granule characteristics in neuronal dendrites.

\section{ALS-linked TDP-43 mutations reduce the trafficking of RNA granules}

Neuronal RNA granules are motile units that traffic along dendrites and interact to control synaptic function cooperatively. These RNA granules regulate RNA transport, translation, and catabolism, thereby controlling local protein synthesis at synapses and synaptic plasticity (Liu-Yesucevitz et al., 2011). We characterized the kinetics of TDP-43 RNA granules using live cell imaging to record the movement of TDP-43 RNA granules. EGFP-tagged TDP-43, A315T, or Q343R were transiently expressed in DIV 10 rat primary hippocampal neurons. Two days after transfection, the neurons imaged to track granule movement. Images were captured every $20 \mathrm{~s}$ for $10 \mathrm{~min}$ and the resulting data were analyzed using multidimensional analysis and single particle tracking applications with MetaMorph software. We observed that the average trafficking velocity of RNA granules containing A315T or Q343R TDP-43 was slower than that of RNA granules containing wild-type TDP-43 (Fig. $3 A$ ). The data were also displayed using a velocity distribution graph (Fig. $3 B$ ). In addition, the ratio of rapidly moving to slowly moving RNA granules was reduced among RNA granules containing mutant TDP-43 (Fig. 3B,C). This shift of movement from rapidly to slowly moving indicates that disease-linked mutations in TDP-43 impair movement RNA granules.

\section{Mutant TDP-43 exhibits reduced dendritic localization upon neuronal depolarization}

Previous results indicated that the localization of TDP- 43 in the dendritic arbor is responsive to neuronal depolarization (Wang et al., 2008). We reasoned that the slower mobility of mutant 


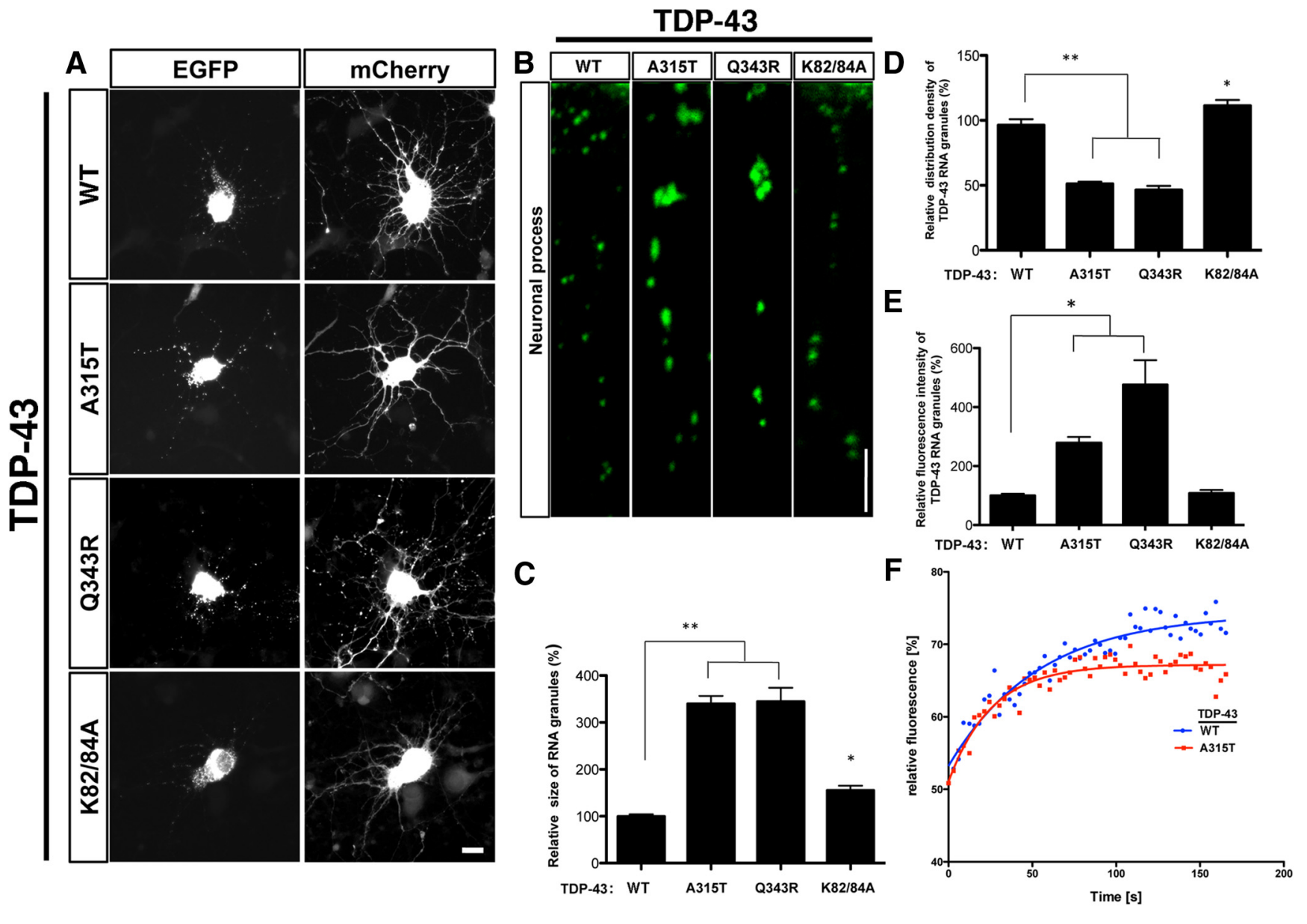

Figure 2. Effects of ALS-linked mutations on the characteristics of TDP-43-enriched RNA granules. A, EGFP-TDP-43 (WT, A315T, Q343R, or K82/84A) was coexpressed with mCherry in DIV 10 rat hippocampal primary neurons. TDP-43 formed RNA granules in neuronal processes. mCherry fluorescence was expressed in the whole neuron and thus was used as a marker to highlight neuronal processes for the quantification of TDP-43 RNA granule distribution density and the furthest neuronal process distance of TDP-43 RNA granules. Scale bar, $10 \mu \mathrm{m}$. $\boldsymbol{B}$, Representative hippocampal neuronal processes expressing TDP-43-enriched RNA granules: WT TDP-43, A315T, and Q343R (ALS-linked TDP-43 mutations) and K82/84A TDP-43 (a mutation removing the nuclear localization signal). Scale bar, $5 \mu \mathrm{m}$. C, Quantification of the average size of TDP-43 RNA granules. RNA granules containing TDP-43 with ALS-linked mutations are larger than those containing WT or K82/84A TDP-43. The average granule size was calculated from $>500$ RNA granules collected from 10 neurons of three independent experiments. ${ }^{*} p=0.01$ WT TDP-43 vs K82/84A TDP-43; ${ }^{* *} p=0.001$ A315T or Q343R vs WT TDP-43. D, Quantification of the average distribution density of TDP-43-enriched RNA granules. The average granule density was calculated from $>30$ processes of 12 different primary hippocampal neurons. ALS-linked mutations significantly reduced the distribution density of RNA granules in neuronal processes. ${ }^{*} p=0.01 \mathrm{WT}$ vs K82/84A TDP-43; ** $p=0.001 \mathrm{A315T}$ or Q343R vs WT TDP-43. Statistical analysis was by one-way ANOVA with Dunnett's posttest. Error bars indicate SEM. E, Quantification of the relative fluorescence intensities of TDP-43 RNA granules in neuronal processes. Data were collected from $>600$ RNA granules from three independent experiments. $F$, FRAP analysis of TDP-43 molecules in RNA granules. Nine primary hippocampal neurons were investigated. The average fluorescence intensities of the irradiated TDP-43 RNA granules after photobleaching of from a representative neuron were plotted over recovery time. The curves were fitted by one-phase exponential equations. The calculated mobile fraction of mutant TDP-enriched RNA granules is lower than those RNA granules containing WT TDP-43.
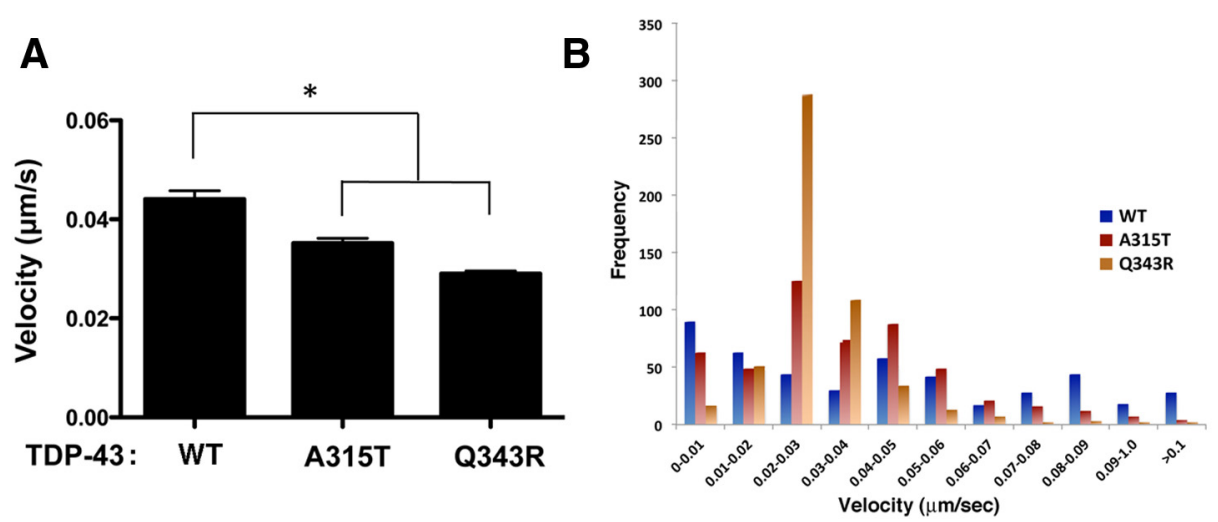

C

\begin{tabular}{|l|c|c|}
\hline $\begin{array}{c}\text { Velocity } \\
\text { (TDP-43) }\end{array}$ & $<\mathbf{0 . 1} \boldsymbol{\mu m} / \mathbf{s}$ & $>\mathbf{0 . 1} \boldsymbol{\mu m} / \mathbf{s}$ \\
\hline WT & $61.69 \%$ & $38.31 \%$ \\
\hline A315T & $78.59 \%$ & $21.41 \%$ \\
\hline Q343R & $94.52 \%$ & $5.49 \%$ \\
\hline
\end{tabular}

Figure 3. ALS-linked TDP-43 mutations exhibit a higher proportion of slower moving RNA granule trafficking. $A$, Velocities of transfected TDP-43::GFP were quantified by measuring the change in position of a granule between two consecutive time-lapse images and dividing the change of distance by the time between images. More than 500 RNA granules from nine different cells were used for quantification. B, C, Velocity distribution of TDP-43::GFP-enriched RNA granules. The velocities from $A$ were categorized into two groups, $>0.1 \mu \mathrm{m} / \mathrm{s}$ and $<0.1 \mu \mathrm{m} / \mathrm{s}$. ALS-linked mutations reduced the number of RNA granules trafficking with velocities $>0.1 \mu \mathrm{m} / \mathrm{s}$. 
TDP-43 might affect its response to neuronal depolarization. To test this, rat hippocampal neurons were transfected with WT or mutant (A315T or Q343R) TDP43. Twenty-four hours after transfection, the neurons were incubated for $1 \mathrm{~h}$ in 1 $\mu \mathrm{M}$ TTX. The cells were then stimulated with $\mathrm{KCl}(90 \mathrm{~mm}, 4 \times 3 \mathrm{~min})$, incubated for $6 \mathrm{~h}$, fixed, and the distribution of TDP-43 was evaluated by immunocytochemistry. The localization of TDP-43 incubated in the presence of TTX but not stimulated by $\mathrm{KCl}$ was nuclear (data not shown). However, after KCl-induced depolarization, WT TDP-43 exhibited extensive dendritic localization (Fig. 4). In contrast, A315T and Q343R TDP-43 exhibited markedly less dendritic localization, reaching distances that were $>70 \%$ less and being present in $70 \%$ fewer processes (Fig. 4). This suggests that the reduced mobility of mutant TDP-43 might interfere with its normal dendritic functions.

\section{Discussion}

Current TDP-43 research largely focuses on understanding its functions in the nucleus and cytoplasm, but in neurons, TDP-43 is expressed abundantly in neuronal processes. However, the specific functions of TDP-43 in the neuronal arbor are poorly understood (Wang et al., 2008). The present study investigated the dendritic biology of TDP-43 and identified strong, mutation-sensitive effects in the neuronal arbor. The discovery of mutation-sensitive dendritic actions suggests novel mechanisms through which disease-linked mutations in TDP-43 might contribute to the pathophysiology of disease.

Our studies of hippocampal neurons show that TDP-43 forms RNA granules in neuronal processes. The observation of mobile TDP-43-positive granules confirms observations by Fallini et al. (2012). The patterns of TDP-43 colocalization with TIA-1 or G3BP differ depending on whether granules are in the dendritic arbor or soma. TDP-43-enriched RNA granules present in dendrites largely colocalized with TIA-1. In contrast, TDP-43 RNA granules present in neuronal soma colocalize with either TIA-1 or G3BP. Colocalization with G3BP is consistent with the known role for TDP-43 in enlarging G3BP RNA granules (McDonald et al., 2011). Therefore, the somatic restriction of granules positive for TDP-43 and G3BP indicates that the molecular composition of TDP-43-enriched RNA granules is variable and suggests different functions for the TDP-43-positive granules in the soma and dendrites. The presence of TDP-43-positive RNA granules in the dendritic arbor is also consistent with prior studies showing an association of TDP-43 with FMRP and staufen in dendrites (Wang et al., 2008). The colocalization with staufen, a protein known to be involved with RNA transport, combined with the mobility of TDP-43 in dendrites, suggests a role for TDP-43positive granules in mRNA transport.

Interestingly, some TDP-43-positive RNA granules also exhibit an intimate interaction with $\mathrm{P}$-bodies, a type of RNA granule responsible for degrading mRNA. These TDP-43 RNA granules were often located adjacent to P-bodies (identified by labeling with Dcpla), but were separate granules not colocalized with P-bodies. A prior study by Wang et al. (2008) suggested that TDP-43 expressed in neuronal processes localizes in P-bodies. However, this conclusion was potentially flawed because the marker used to identify P-bodies, GW182 (a component of the RNA-induced silencing complex), is now known to identify endosomes and multivesicular bodies (Gibbings et al., 2009). Integration of these data suggests that TDP-43 interacts with, but does not actually colocalize with, P-bodies and suggests the heterogeneous nature of TDP-43 RNA granules.

The biology of RNA-binding proteins such as TDP-43 is fundamentally linked to protein aggregation (Wolozin, 2012). RNAbinding proteins consolidate transcripts by aggregating to form granules through a process that we have termed regulated protein aggregation (Wolozin, 2012). Most disease-linked mutations in TDP-43, as well as other RNA-binding proteins, appear to increase the tendency of these proteins to aggregate, which effectively shifts the equilibrium between dispersed and aggregated states and leads to larger RNA granules, including stress granules (Johnson et al., 2009; Elden et al., 2010; Liu-Yesucevitz et al., 2010; Bosco et al., 2010; Wolozin, 2012; Kim et al., 2013). Recent work by Donnelly et al. (2013) suggests that C9ORF72 might also 
contribute to the pathophysiology of ALS through a similar mechanism involving sequestration of RNA-binding proteins. Upon investigating MN iPSCs carrying G298S TDP-43, we observed evidence of increasing TDP-43 aggregation with increasing duration of culture under differentiating conditions. Although no statistically significant differences in insoluble TDP-43 or granule number was observed in young MN iPSC cultures, cells from a G298S TDP-43 line that had been grown in culture under differentiating conditions longer showed readily detectable insoluble multimeric TDP-43. These results are consistent with prior studies on iPSCs and suggest that disease-linked mutations increase the tendency of TDP-43 to aggregate under conditions of endogenous expression (Bilican et al., 2012; Egawa et al., 2012). We also observed smaller TDP-43 fragments, which might appear to correspond to the 25 and $35 \mathrm{kDa}$ cleavage fragments noted previously (Neumann et al., 2006; Zhang et al., 2009).

The neuronal predominance of ALS pathology suggests a fundamental link between neuronal biology and the pathophysiology of ALS. The link might lie in the strong propensity of neurons to constitutively form RNA granules in the cytoplasm and neuronal arbor. We reasoned that mutation-induced changes in the equilibrium between dispersed and aggregated might alter the dynamics of neuronal TDP-43 RNA granules. Our studies demonstrate that ALS-linked mutations (A315T and Q343R) increased the average size and decreased the distribution density of TDP-43 RNA granules in neuronal processes. These changes in RNA granules appear to result from structural features in TDP-43 rather than the amount of cytoplasmic TDP-43, because the K82/84A mutation, which removes the nuclear localization signal, generates high levels of cytoplasmic TDP-43 yet does not alter the average granule size or distribution density. The changes in RNA granules also extended to movement. Live-cell-imaging studies showed strong changes in mobility. Mutant TDP-43 granules showed a much higher proportion of immobile RNA granules. In addition, FRAP analysis demonstrated that RNA granules containing mutant TDP-43 are less mobile than those with WT TDP-43, which is consistent with the increased granule size. Mutation-related differences in RNA granule dynamics might affect the biology of neurons because these RNA granules are thought to play important roles in transporting transcripts along the complex network of neuronal dendrites, dendritic boutons, and synapses. The granules also play important roles in activity-dependent translation and synaptic plasticity (Kiebler and Bassell, 2006; Wang et al., 2008; Liu-Yesucevitz et al., 2011; Pascual et al., 2012; Fallini et al., 2012). Each of these activities is dependent on the process of regulated protein aggregation, which modulates the size, distribution, and, ultimately, function of the RNA granules in the neuronal arbor.

The issue of mobility becomes particularly important when considering physiological responses to neural activity. Studies by Wang et al. (2008) indicated strong translocation of TDP-43 to the dendritic arbor upon depolarization of neurons with $\mathrm{KCl}$. Our studies confirmed these results and also demonstrated a striking $70 \%$ decrease of dendritic translocation of mutant TDP-43 (A315T and Q343R) in response to depolarization (Fig. 4). Although the experiments did not use live cell imaging, the decreased translocation is consistent with the overall reduction in movement of mutant TDP-43. Therefore, mutation-induced increases in the propensity of TDP-43 to aggregate results in slower moving neuronal granules. These results suggest that diseaselinked TDP-43 mutations modify its biology in the neuronal arbor before overt degeneration, which suggests potential mechanisms for early pathophysiological changes occurring in ALS.

Recent studies with cases of familial Alzheimer's disease indicate that the early stages of neuron dysfunction in neurodegenerative diseases begin decades before the presentation of clinical syndromes (Acosta-Baena et al., 2011) and the same may be true for ALS. Genetic studies suggest roles for TDP-43 in neuronal biology. TDP-43 has been shown to bind multiple transcripts, including multiple transcripts related neurons function, such as Park2, Nlgn1, GluA2, and Nrxn3 (Polymenidou et al., 2011; Lagier-Tourenne et al., 2012). The observation that mutations in TDP-43 alter the dynamics of neuronal RNA granules raises the possibility that the pathophysiology of ALS affects other aspects of neuronal function before overt neurodegeneration occurs. Time lapse studies of transfected neurons shows that cytoplasmic TDP-43 is a better predictor of degeneration than nuclear TDP-43 (Barmada et al., 2010). This "extranuclear" activity extends well beyond the immediate neuronal soma. In synapses, TDP-43 acts as a neuronal activity-responsive factor that changes its localization at synapses in response to stimulation (Wang et al., 2008). More recently, TDP-43-enriched RNA granules were proposed to be categorized as synaptic-activityregulated foci that might regulate local protein synthesis at the synapses (Fallini et al., 2012; Pascual et al., 2012; Wolozin, 2012). Our results suggest strong effects of disease-linked mutations on the behavior of TDP-43 in the dendritic arbor and reveal that disease-linked TDP-43 mutations reduce or slow the response of TDP-43 to changes in neuronal activity. These results demonstrate a discrete activity of TDP-43 in an extranuclear, neuronal compartment that is affected by disease-linked mutations in TDP-43. Therefore, although end-stage TDP-43 pathology occurs in the soma or nucleus, the pathophysiology of TDP-43 could be manifest in dendrites and synapses potentially much earlier in the course of disease.

\section{References}

Acosta-Baena N, Sepulveda-Falla D, Lopera-Gómez CM, Jaramillo-Elorza MC, Moreno S, Aguirre-Acevedo DC, Saldarriaga A, Lopera F (2011) Pre-dementia clinical stages in presenilin 1 E280A familial early-onset Alzheimer's disease: a retrospective cohort study. Lancet Neurol 10:213220. CrossRef Medline

Barmada SJ, Skibinski G, Korb E, Rao EJ, Wu JY, Finkbeiner S (2010) Cytoplasmic mislocalization of TDP-43 is toxic to neurons and enhanced by a mutation associated with familial amyotrophic lateral sclerosis. J Neurosci 30:639-649. CrossRef Medline

Bentmann E, Neumann M, Tahirovic S, Rodde R, Dormann D, Haass C (2012) Requirements for stress granule recruitment of fused in sarcoma (FUS) and TAR DNA-binding protein of $43 \mathrm{kDa}$ (TDP-43). J Biol Chem 287:23079-23094. CrossRef Medline

Bilican B, Serio A, Barmada SJ, Nishimura AL, Sullivan GJ, Carrasco M, Phatnani HP, Puddifoot CA, Story D, Fletcher J, Park IH, Friedman BA, Daley GQ, Wyllie DJ, Hardingham GE, Wilmut I, Finkbeiner S, Maniatis T, Shaw CE, Chandran S (2012) Mutant induced pluripotent stem cell lines recapitulate aspects of TDP-43 proteinopathies and reveal cellspecific vulnerability. Proc Natl Acad Sci U S A 109:5803-5808. CrossRef Medline

Bosco DA, Lemay N, Ko HK, Zhou H, Burke C, Kwiatkowski TJ Jr, Sapp P, McKenna-Yasek D, Brown RH Jr, Hayward LJ (2010) Mutant FUS proteins that cause amyotrophic lateral sclerosis incorporate into stress granules. Hum Mol Genet 19:4160-4175. CrossRef Medline

Chambers SM, Fasano CA, Papapetrou EP, Tomishima M, Sadelain M, Studer L (2009) Highly efficient neural conversion of human ES and iPS cells by dual inhibition of SMAD signaling. Nat Biotechnol 27:275-280. CrossRef Medline

Colombrita C, Zennaro E, Fallini C, Weber M, Sommacal A, Buratti E, Silani $\mathrm{V}$, Ratti A (2009) Tdp-43 is recruited to stress granules in conditions of oxidative insult. J Neurochem 111:1051-1061. CrossRef Medline 
Da Cruz S, Cleveland DW (2011) Understanding the role of TDP-43 and FUS/TLS in ALS and beyond. Curr Opin Neurobiol 21:904-919. CrossRef Medline

Dewey CM, Cenik B, Sephton CF, Dries DR, Mayer P 3rd, Good SK, Johnson BA, Herz J, Yu G (2011) TDP-43 is directed to stress granules by sorbitol, a novel physiological osmotic and oxidative stressor. Mol Cell Biol 31:1098-1108. CrossRef Medline

Donnelly CJ, Zhang PW, Pham JT, Heusler AR, Mistry NA, Vidensky S, Daley EL, Poth EM, Hoover B, Fines DM, Maragakis N, Tienari PJ, Petrucelli L, Traynor BJ, Wang J, Rigo F, Bennett CF, Blackshaw S, Sattler R, Rothstein JD (2013) RNA toxicity from the ALS/FTD C9ORF72 expansion is mitigated by antisense intervention. Neuron 80:415-428. CrossRef Medline

Egawa N, Kitaoka S, Tsukita K, Naitoh M, Takahashi K, Yamamoto T, Adachi F, Kondo T, Okita K, Asaka I, Aoi T, Watanabe A, Yamada Y, Morizane A, Takahashi J, Ayaki T, Ito H, Yoshikawa K, Yamawaki S, Suzuki S, et al. (2012) Drug screening for ALS using patient-specific induced pluripotent stem cells. Sci Transl Med 4:145ra104. CrossRef Medline

Elden AC, Kim HJ, Hart MP, Chen-Plotkin AS, Johnson BS, Fang X, Armakola M, Geser F, Greene R, Lu MM, Padmanabhan A, Clay-Falcone D, McCluskey L, Elman L, Juhr D, Gruber PJ, Rüb U, Auburger G, Trojanowski JQ, Lee VM, et al. (2010) Ataxin-2 intermediate-length polyglutamine expansions are associated with increased risk for ALS. Nature 466:1069-1075. CrossRef Medline

Fallini C, Bassell GJ, Rossoll W (2012) The ALS disease protein TDP-43 is actively transported in motor neuron axons and regulates axon outgrowth. Hum Mol Genet 21:3703-3718. CrossRef Medline

Gibbings DJ, Ciaudo C, Erhardt M, Voinnet O (2009) Multivesicular bodies associate with components of miRNA effector complexes and modulate miRNA activity. Nat Cell Biol 11:1143-1149. CrossRef Medline

Hart MP, Gitler AD (2012) ALS-associated Ataxin 2 PolyQ expansions enhance stress-induced Caspase 3 activation and increase TDP-43 pathological modifications. J Neurosci 32:9133-9142. CrossRef Medline

Hu BY, Du ZW, Li XJ, Ayala M, Zhang SC (2009) Human oligodendrocytes from embryonic stem cells: conserved SHH signaling networks and divergent FGF effects. Development 136:1443-1452. CrossRef Medline

Johnson BS, Snead D, Lee JJ, McCaffery JM, Shorter J, Gitler AD (2009) TDP-43 is intrinsically aggregation-prone, and amyotrophic lateral sclerosis-linked mutations accelerate aggregation and increase toxicity. J Biol Chem 284:20329-20339. CrossRef Medline

Kiebler MA, Bassell GJ (2006) Neuronal RNA granules: movers and makers. Neuron 51:685-690. CrossRef Medline

Kim HJ, Kim NC, Wang YD, Scarborough EA, Moore J, Diaz Z, MacLea KS, Freibaum B, Li S, Molliex A, Kanagaraj AP, Carter R, Boylan KB, Wojtas AM, Rademakers R, Pinkus JL, Greenberg SA, Trojanowski JQ, Traynor BJ, Smith BN, et al. (2013) Mutations in prion-like domains in hnRNPA2B1 and hnRNPA1 cause multisystem proteinopathy and ALS. Nature 495:467-473. CrossRef Medline

King OD, Gitler AD, Shorter J (2012) The tip of the iceberg: RNA-binding proteins with prion-like domains in neurodegenerative disease. Brain Res 1462:61-80. CrossRef Medline

Lagier-Tourenne C, Polymenidou M, Hutt KR, Vu AQ, Baughn M, Huelga SC, Clutario KM, Ling SC, Liang TY, Mazur C, Wancewicz E, Kim AS, Watt A, Freier S, Hicks GG, Donohue JP, Shiue L, Bennett CF, Ravits J, Cleveland DW, et al. (2012) Divergent roles of ALS-linked proteins FUS/TLS and TDP-43 intersect in processing long pre-mRNAs. Nat Neurosci 15:1488-1497. CrossRef Medline

Leung A, Nah SK, Reid W, Ebata A, Koch CM, Monti S, Genereux JC, Wiseman RL, Wolozin B, Connors LH, Berk JL, Seldin DC, Mostoslavsky G,
Kotton DN, Murphy GJ (2013) Induced pluripotent stem cell modeling of multisystemic, hereditary transthyretin amyloidosis. Stem Cell Reports 1:451-463. CrossRef Medline

Liu-Yesucevitz L, Bilgutay A, Zhang YJ, Vanderweyde T, Citro A, Mehta T, Zaarur N, McKee A, Bowser R, Sherman M, Petrucelli L, Wolozin B (2010) Tar DNA binding protein-43 (TDP-43) associates with stress granules: analysis of cultured cells and pathological brain tissue. PLoS One 5:e13250. CrossRef Medline

Liu-Yesucevitz L, Bassell GJ, Gitler AD, Hart AC, Klann E, Richter JD, Warren ST, Wolozin B (2011) Local RNA translation at the synapse and in disease. J Neurosci 31:16086-16093. CrossRef Medline

McDonald KK, Aulas A, Destroismaisons L, Pickles S, Beleac E, Camu W, Rouleau GA, Vande Velde C (2011) TAR DNA-binding protein 43 (TDP-43) regulates stress granule dynamics via differential regulation of G3BP and TIA-1. Hum Mol Genet 20:1400-1410. CrossRef Medline

Meijering E, Jacob M, Sarria JC, Steiner P, Hirling H, Unser M (2004) Design and validation of a tool for neurite tracing and analysis in fluorescence microscopy images. Cytometry A 58:167-176. CrossRef Medline

Neumann M, Sampathu DM, Kwong LK, Truax AC, Micsenyi MC, Chou TT, Bruce J, Schuck T, Grossman M, Clark CM, McCluskey LF, Miller BL, Masliah E, Mackenzie IR, Feldman H, Feiden W, Kretzschmar HA, Trojanowski JQ, Lee VM (2006) Ubiquitinated TDP-43 in frontotemporal lobar degeneration and amyotrophic lateral sclerosis. Science 314:130133. CrossRef Medline

Pascual ML, Luchelli L, Habif M, Boccaccio GL (2012) Synaptic activity regulated mRNA-silencing foci for the fine tuning of local protein synthesis at the synapse. Commun Integr Biol 5:388-392. CrossRef Medline

Polymenidou M, Lagier-Tourenne C, Hutt KR, Huelga SC, Moran J, Liang TY, Ling SC, Sun E, Wancewicz E, Mazur C, Kordasiewicz H, Sedaghat Y, Donohue JP, Shiue L, Bennett CF, Yeo GW, Cleveland DW (2011) Long pre-mRNA depletion and RNA missplicing contribute to neuronal vulnerability from loss of TDP-43. Nat Neurosci 14:459-468. CrossRef Medline

Schneider CA, Rasband WS, Eliceiri KW (2012) NIH Image to ImageJ: 25 years of image analysis. Nat Methods 9:671-675. CrossRef Medline

Sommer CA, Stadtfeld M, Murphy GJ, Hochedlinger K, Kotton DN, Mostoslavsky G (2009) Induced pluripotent stem cell generation using a single lentiviral stem cell cassette. Stem Cells 27:543-549. CrossRef Medline

Sommer CA, Sommer AG, Longmire TA, Christodoulou C, Thomas DD, Gostissa M, Alt FW, Murphy GJ, Kotton DN, Mostoslavsky G (2010) Excision of reprogramming transgenes improves the differentiation potential of iPS cells generated with a single excisable vector. Stem Cells 28:64-74. CrossRef Medline

Sprague BL, McNally JG (2005) FRAP analysis of binding: proper and fitting. Trends Cell Biol 15:84-91. CrossRef Medline

Wang IF, Wu LS, Chang HY, Shen CK (2008) TDP-43, the signature protein of FTLD-U, is a neuronal activity-responsive factor. J Neurochem 105: 797-806. CrossRef Medline

Watanabe S, Kaneko K, Yamanaka K (2013) Accelerated disease onset with stabilized familial amyotrophic lateral sclerosis (ALS)-linked mutant TDP-43 proteins. J Biol Chem 288:3641-3654. CrossRef Medline

Wolozin B (2012) Regulated protein aggregation: stress granules and neurodegeneration. Mol Neurodegener 7:56. CrossRef Medline

Zhang YJ, Xu YF, Cook C, Gendron TF, Roettges P, Link CD, Lin WL, Tong J, Castanedes-Casey M, Ash P, Gass J, Rangachari V, Buratti E, Baralle F, Golde TE, Dickson DW, Petrucelli L (2009) Aberrant cleavage of TDP-43 enhances aggregation and cellular toxicity. Proc Natl Acad Sci U S A 106:7607-7612. CrossRef Medline 